\title{
PENGARUH BENTUK GEOMETRI PEMASANGAN LAMPU LED TERHADAP AKURASI INDOOR PSITIONING LI-FI MENGGUNAKAN TEKNIK RECEIVE SIGNAL STRENGTH (RSS)
}

\author{
Jaka Satria Prayuda $^{1}$, Denny Darlis ${ }^{2}$, Akhmad Hambali $^{3}$ \\ 1, ${ }^{3}$ Fakultas Teknik Elektro, Universitas Telkom, Bandung, Indonesia \\ ${ }^{2}$ Fakultas Ilmu Terapan, Universitas Telkom, Bandung, Indonesia \\ 1 jakasatriaprayuda@student.telkomuniversity.ac.id, ${ }^{2}$ denny.darlis@ tass.telkomuniversity.ac.id, \\ 3ahambali@telkomuniversity.ac.id
}

\begin{abstract}
Abstrak
Informasi untuk mengetahui lokasi benda atau seseorang merupakan salah satu hal yang penting dalam kehidupan sehari-hari. Selama ini, teknologi Global Positioning System (GPS) dapat diandalkan ketika berada di luar ruangan. Namun, ketika di dalam ruangan, GPS akan sulit menjangkau secara spesifik area bangunan. Dengan memanfaatkan teknologi Light Fidelity (Li-Fi), Indoor Positioning System (IPS) akan lebih mudah dilakukan dan mempunyai keunggulan dari segi akurasi dan efisiensi energi. Tetapi, jika dikaitkan dengan IPS, pemasangan lampu Light Emitting Diode (LED) perlu diperhatikan geometri pemasangannya. Penelitian ini membahas akurasi IPS pada Li-Fi apabila dengan berbagai bentuk geometri dan lokasi pemasangan lampu LED yang berbeda-beda. Teknik positioning Received Signal Strength (RSS) digunakan dengan mengambil kuat daya terima sebagai estimasi suatu jarak. Dengan membandingkan masing-masing bentuk geometri, maka didapatkan data konfigurasi terbaik untuk implementasi IPS. Hasil penelitian menunjukkan bahwa perbedaan jumlah lampu LED dan bentuk geometri akan berpengaruh terhadap akurasi positioning. Hasil menunjukkan bahwa geometri segi enam memiliki rata-rata error yang lebih kecil dibandingkan geometri yang lain, yakni sebesar $1,53 \times 10^{-05} \mathbf{m}$. Semakin banyak lampu LED atau poin referensi dengan rentang jarak lampu yang lebih rapat, maka dapat menghasilkan positioning yang lebih baik.
\end{abstract}

Kata Kunci: Light Fidelity (Li-Fi), Indoor Positioning System (IPS), Received Signal Strength (RSS), Geometri.

\section{Abstract}

Knowing the location of objects or someone is important in daily life. Global Positioning System (GPS) technology is usually used to know the position of an object, but it is reliable at outdoors only. When indoors, the GPS will difficult to reach specific areas of the building, due to their lack of accuracies. By utilizing Light Fidelity (Li-Fi) technology, Indoor Positioning System (IPS) could be done and it also has advantages in terms of accuracy and energy efficiency. However, the use of IPS should considers the Light Emitting Diode (LED) installation as well as its geometry and location. This research discusses the relation of IPS accuracy in Li-Fi when the geometry shape of the LED lamps installation location was varied. The positioning technique Received Signal Strength (RSS) was used, which takes strong receiving power as an estimate of a distance. By comparing each geometry, then the best configuration data could be obtained for thr implementation of IPS. The results showed that the differences in the number of LED lamps and geometry affected the positioning accuracy. The experiment results showed that the geometry of the hexagon has an average of less error positioning, compared to other geometries and the value is $1,53 \times 10^{-05} \mathbf{m}$. The more LED lights of reference points with a more tightly-spaced range resulted in better positioning.

Key Words: Light Fidelity (Li-Fi), Indoor Positioning System (IPS), Received Signal Strength (RSS), Geometry.

1. Pendahuluan

Berdasarkan data dari Ericsson, hasil survey n dari 23 negara menunjukkan bahwa, manusia cenderung menghabiskan hampir $85 \%$ waktunya untuk beraktivitas di dalam ruangan termasuk di dalamnya dalam penggunaan internet secara indoor adalah 77\% [1]. 
Mengaitkan ini dengan konsep society 5.0, yaitu dimana masyarakat berorientasi pada teknologi, dapat dipastikan sangat diperlukannya kebutuhan akses data yang cepat dan ditunjang oleh aplikasi aktivitas manusia, yang salah satunya adalah indoor positioning system (IPS).

IPS merupakan sebuah konsep komunikasi yang digunakan untuk mengetahui lokasi benda atau seseorang di dalam ruangan. dariJika IPS ini diimplementasikan, maka keandalan akurasi dan efisiensi energi perlu diperhatikan. Selama ini, teknologi Global Positioning System (GPS) dapat diandalkan ketika berada di luar ruangan. Namun, ketika di dalam ruangan, GPS akan sulit menjangkau secara spesifik area bangunan tertentu, dikarenakan akurasinya yang terbatas dan tergantung oleh situasi lingkungan. Kebutuhan IPS muncul sebagai pelengkap navigasi pada teknologi GPS. Aplikasi IPS ini di antaranya adalah dapat mengarahkan pengunjung di suatu museum, toko perbelanjaan, dan membantu tunanetra mengenali lingkungan suatu ruangan untuk keperluan navigasi $[2,3]$.

Terdapat beberapa teknologi yang dapat mendukung IPS seperti Wireless Fidelity (Wi-Fi), Bluetooth Low Energy (BLE), dan Light Fidelity (Li-Fi). Dari teknologi-teknologi tersebut, teknologi Li-Fi mempunyai keunggulan yang lebih dari segi akurasi dan efisiensi energi $[4,5]$. Keunggulan lainnya adalah terkait aspek availability, dimana hampir setiap lokasi mempunyai perangkat untuk penerangan, serta memungkinkan diaplikasikan pada area yang tidak bisa dijangkau frekuensi radio. Selain itu, keunggulannya adalah aspek "capacity" bandwidth yang lebih lebar dibandingkan frekuensi radio, dan aspek security yang baik karena tidak dapat menembus objek solid. Li-Fi merupakan bagian dari teknologi Visible Light Communication (VLC) yang memanfaatkan lampu Light Emitting Diode (LED) sebagai media penerangan dan transmisi data secara bersamaan. Li-Fi berfokus pada bi-directional multiuser communication dibandingkan VLC yang hanya pada point to point communication [6].

Terdapat beberapa teknik positioning yang dapat digunakan pada $\mathrm{Li}-\mathrm{Fi}$, di antaranya adalah: triangulation, scene analysis, dan proximity [8]. Pada penelitian ini, teknik triangulation digunakan. Pada angulation, informasi didapatkan menggunakan sifat geometri segitiga, dan lateration, dimana estimasi posisi didapatkan dari beberapa poin referensi. Permasalahan yang muncul ketika Teknik ini dikaitkan dengan IPS adalah, pada umumnya lokasi pemasangan lampu LED mengikuti bentuk ruangan itu sendiri. Hal tersebut bagaimanapun secara tidak langsung akan mempengaruhi akurasi, jika terkait Received Signal Strength (RSS) yang mengambil kuat daya terima sebagai estimasi suatu jarak.

Oleh sebab itu, pada penelitian ini dibahas lebih lanjut antara hubungan akurasi IPS pada Li-Fi dengan

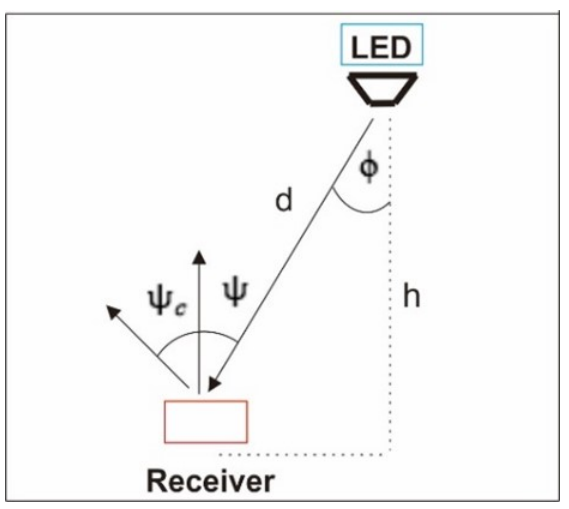

Gambar 1. Kanal LOS.

skenario berbagai bentuk geometri pemasangan lampu LED menggunakan teknik RSS. Adapun pertimbangan menggunakan teknik RSS ini adalah karena lebih sederhana, hemat biaya, dan sering digunakan untuk model kanal Line of Sight (LOS) [7]. Dari penelitian ini, diharapkan dapat diperoleh informasi konfigurasi terbaik untuk implementasi IPS pada teknologi Li-Fi.

\section{Dasar Teori}

\subsection{Kanal Line of Sight (LOS)}

Gambar 1 memperlihatkan model kanal LOS yang digunakan pada penelitian ini. Terdapat dua komponen utama, yakni lampu LED dan optical receiver. Lampu LED berfungsi sebagai transmitter yang akan melakukan penerangan dan transmisi data secara simultan. Dalam positioning, komponen transmitter mempunyai kapabilitas untuk mengirimkan ID unik terkait lokasi fisik mereka. Hal ini sangat bermanfaat untuk identifikasi masing-masing dari transmitter. Informasi tersebut selanjutnya akan diterima oleh optical receiver yang terpasang pada sebuah device untuk kemudian diproses.

Saat komunikasi berlangsung, kanal LOS terjadi ketika tidak ada objek penghalang dan tidak memperhatikan pantulan antara transmitter dan receiver. $\phi$ adalah sudut radiasi yang terbentuk terhadap normal axis transmitter, $\psi$ adalah sudut insiden yang terbentuk terhadap normal axis receiver, $\psi_{c}$ adalah Field of View (FOV) semi-angle.

Daya terima pada pada kanal LOS dapat diekspresikan pada persamaan (1), (2) dan (3) berikut,

$$
\begin{gathered}
P_{L O S}= \begin{cases}P_{t x} \cdot \frac{(m+1)}{2 \pi \cdot d^{2}} A \cdot G \cdot \cos ^{m}(\phi) \cdot \cos (\psi), & 0 \leq \psi \leq \psi c \\
0, & \text { lainnya }\end{cases} \\
G=T_{s}(\psi) \cdot g(\psi), \\
P_{t x}=P_{t} \cdot \eta_{O O K}
\end{gathered}
$$

Dengan $P_{t x}$ adalah daya kirim lampu LED dengan memperhitungkan modulation depth on-off keying 
$\left(\eta_{\text {Оок }}\right)$ sebesar $12.5 \%$ untuk meminimalisir masalah flicker $[8,9] . \quad P_{t}$ adalah rata-rata dari lampu LED A adalah luas area photodetector, $d$ adalah jarak propagasi antara transmitter dan receiver, $T_{s}(\psi)$ adalah optical filter gain, $g(\psi)$ adalah gain concentrator, dan $m$ adalah lambertian emission. $P_{t x}$ dapat dicari dengan:,

$$
P_{t x}=P_{t} \cdot \eta_{O O K}
$$

\subsection{Received Signal Strength (RSS)}

RSS merupakan teknik estimasi jarak yang melakukan pengukuran kuat daya sinyal sebagai bahan pertimbangannya. Daya yang diterima akan merepresentasikan fungsi jarak dari pengirim terhadap penerima. Seperti yang diusulkan [10], dengan asumsi posisi transmitter adalah tegak lurus terhadap receiver, maka persamaan (1) dapat juga disajikan seperti persamaan (4):

$$
P_{\text {LOS }}= \begin{cases}P_{t x} \cdot \frac{(m+1)}{2 \pi \cdot d^{(\mathrm{m}+3)}} A \cdot h^{(\mathrm{m}+1)} \cdot G, & 0 \leq \psi \leq \psi c \\ 0, & \text { lainnya }\end{cases}
$$

Output daya dari perangkat photodetector dapat dinyatakan sebagai $P_{\text {electrical }}=\left(R \cdot P_{L O S}\right)^{2}$. Estimasi jarak antara transmitter dan receiver dapat dinyatakan seperti persamaan (5) berikut:

$$
d_{\text {est }}=\sqrt[2 m+6]{\frac{\left[R \cdot P_{t x} \cdot(m+1) \cdot A \cdot G \cdot h^{m+1}\right]^{2}}{4 \pi^{2} \cdot P_{\text {electrical }}}} .
$$

dengan $h$ adalah jarak vertikal antara transmitter dan receiver. Selanjutnya, estimasi posisi dapat dihitung dengan metode circular lateration. Untuk menghasilkan estimasi posisi setidaknya diperlukan tiga sumber transmitter (trilateration), dimana setiap transmitter mempunyai daerah cakupan tertentu yang saling beririsan. Trilateration adalah hal yang harus dipenuhi dalam proses positioning. Tetapi, pada implementasinya, dapat digunakan juga lebih dari tiga sumber transmitter atau disebut multilateration. Trilateration dapat dinyatakan pada persamaan (6) berikut [11],

$$
\begin{aligned}
& \left(x_{R}-x_{1}\right)^{2}+\left(y_{R}-y_{1}\right)^{2}=d_{\text {est }-1}^{2} \\
& \left(x_{R}-x_{2}\right)^{2}+\left(y_{R}-y_{2}\right)^{2}=d_{\text {est }-2}^{2} \\
& \left(x_{R}-x_{3}\right)^{2}+\left(y_{R}-y_{3}\right)^{2}=d_{\text {est }-3}^{2},
\end{aligned}
$$

dengan $\left[x_{R}, y_{R}\right]$ adalah koordinat receiver, dan $\left[x_{i}, y_{i}\right]$ adalah koordinat ke $i$ lampu LED. Hasil ketiga persamaan tersebut dapat dinyatakan sebagai matriks (7) berikut:

$$
\begin{aligned}
& A X=B, \\
& A=\left(\begin{array}{ll}
x_{2}-x_{1} & y_{2}-y_{1} \\
x_{3}-x_{1} & y_{2}-y_{1}
\end{array}\right), X=\left(\begin{array}{c}
x_{R} \\
y_{R}
\end{array}\right), \\
& B=\frac{1}{2}\left(\begin{array}{c}
x_{1}^{2}-x_{3}^{2}+y_{1}^{2}-y_{3}^{2}-d_{\text {est }-1}^{2}+d_{\text {est }-3}^{2} \\
x_{2}^{2}-x_{3}^{2}+y_{2}^{2}-y_{3}^{2}-d_{\text {est }-2}^{2}+d_{\text {est }-3}^{2}
\end{array}\right) .
\end{aligned}
$$

Koordinat estimasi posisi akhirnya dapat diketahui dengan metode least linear square oleh persamaan (8) berikut:

$$
X=\left(A^{T} A\right)^{-1} \cdot A^{T} B .
$$

\subsection{Noise Model}

Noise pada sistem VLC/Li-Fi dapat diklasifikasikan menjadi dua kategori, yakni noise dari cahaya, termasuk di dalamnya noise kuantum dari sinyal optik itu sendiri, noise background radiation dari cahaya ambient, dan noise dari perangkat receiver seperti noise dark current, thermal noisel, dan 1/fnoise [12].

Model noise yang dibangkitkan pada penelitian ini mengacu pada [10] dan [13], yang memuat noise dark current $\left(\sigma_{D C}^{2}\right)$, noise background radiation $\left(\sigma_{B G}^{2}\right)$, noise sinyal terima $\left(\sigma_{S S}^{2}\right)$, dan thermal noise $\left(\sigma_{T H}^{2}\right)$.

Noise quantum atau sinyal terima disebabkan oleh sifat diskrit foton dari sumber optik. Dark current adalah arus listrik yang ada pada photodiode bahkan ada ketika tidak ada insiden cahaya. Hal ini disebabkan oleh generasi acak dari pasangan hole-electron atau tunneling antara pita konduksi dan pita valensi. Noise background radiation disebabkan oleh penerimaan foton dari lingkungan. Sumber cahaya lingkungan dapat berupa matahari, langit, lampu pijar, dsb. Thermal noise disebabkan oleh fluktuasi acak dari pembawa muatan (biasanya elektron) dalam suatu media pada suhu yang lebih tinggi dari suhu nol mutlak.

Masing-masing persamaan noise disajikan dalam persamaan (9), (10), (11) dan (12) berikut [10, 13]:

$$
\begin{gathered}
\sigma_{D C}^{2}=2 q I_{D C} B, \\
\sigma_{B G}^{2}=2 q R p_{B S} A \Delta_{\lambda} B, \\
\sigma_{S S}^{2}=2 q R\left(P_{r e c}\right) B, \\
\sigma_{T H}^{2}=\frac{8 \pi k T}{G_{0}} \eta A I_{2} B^{2}+\frac{16 \pi^{2} k T \Gamma}{g_{m}} \eta^{2} A^{2} I_{3} B^{3},
\end{gathered}
$$

dengan $q$ adalah muatan elektron, $I_{D C}$ adalah dark current dari photodetector, $B$ adalah bandwidth, $R$ adalah responsivitas photodetector, $p_{B S}$ adalah background spectral irradiance, $\Delta_{\lambda}$ adalah bandwidth dari optical filter, Prec adalah daya terima sinyal optik, $k$ adalah konstanta Boltzman $\left(1.38 \times 10^{-23} \mathrm{~J} / K\right), T$ adalah suhu absolut, $G_{0}$ adalah open-loop voltage gain, $\eta$ adalah fixed capacitance dari photodetector per unit area, $\Gamma$ adalah kanal faktor noise dari FET, $g_{m}$ adalah transkonduktansi FET, $I_{2}=0.562$, dan $I_{3}=0.0868$.

\section{Model Sistem dan Perancangan}

\subsection{Model Sistem}

Konsep sistem yang dirancang ditunjukkan pada Gambar 2. Kondisi komunikasi yang terjadi dalam skenario, yakni kanal bersifat LOS dan tidak ada penghalang, sehingga tidak memperhatikan faktor 


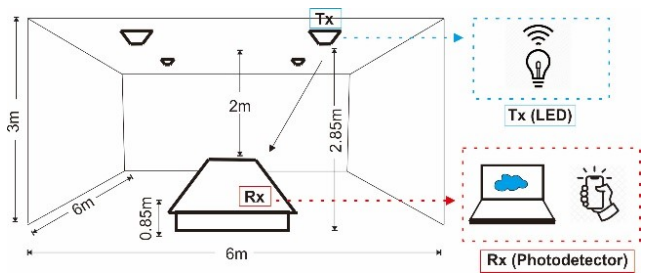

Gambar 2. Model Sistem

refleksi dan scattering. Kondisi ruangan diasumsikan tidak ada faktor sumber cahaya lain secara spesifik. Tabel 1 memuat parameter terkait lokasi lampu LED yang digunakan, sedangkan Tabel 2 memuat parameter terkait spesifikasi transmitter, receiver, dan konfigurasi sistem.

Tabel 1. Koordinat LED

\begin{tabular}{|c|c|c|}
\hline $\begin{array}{c}\text { Bentuk } \\
\text { Geometri }\end{array}$ & Teknik & Koordinat (m) \\
\hline Segitiga & \multirow{2}{*}{ Trilateral } & $\begin{array}{c}(0 ;-1,5 ; 2,85) \\
(2 ; 1,5 ; 2,85) \\
(-2 ; 1,5 ; 2,85)\end{array}$ \\
\hline $\begin{array}{l}\text { Berderet } \\
\text { Memanjang }\end{array}$ & & $\begin{array}{c}(0 ;-1,5 ; 2,85) \\
(0 ; 0 ; 2,85)- \\
(0 ; 1,5 ; 2,85)\end{array}$ \\
\hline Bujur Sangkar & \multirow{3}{*}{ Multilateral } & $\begin{array}{c}(-1,5 ;-1,5 ; 2,85)- \\
(-1,5 ; 1,5 ; 2,85), \\
(1,5 ;-1,5 ; 2,85), \\
(1,5 ; 1,5 ; 2,85)\end{array}$ \\
\hline Segi lima & & $\begin{array}{c}(0 ; 2 ; 2,85) \\
(-1,5 ; 0 ; 2,85) \\
(1,5 ; 0 ; 2,85) \\
(-1 ;-2 ; 2,85) \\
(1 ;-2 ; 2,85)\end{array}$ \\
\hline Segi enam & & $\begin{array}{c}(-1,5 ;-1 ; 2,85), \\
(-1,5 ; 1 ; 2,85), \\
(1,5 ;-1 ; 2,85), \\
(1,5 ; 1 ; 2,85), \\
(0 ; 2 ; 2,85), \\
(0 ;-2 ; 2,85)\end{array}$ \\
\hline
\end{tabular}

\subsection{Diagram Alir Sistem}

Gambar 3 memperlihatkan diagram alir sistem, secara garis besar tahapan tersebut adalah:

1. Inisialisasi Parameter dan Skenario Sistem

Pada penelitian ini digunakan LED sebanyak 3-6 buah, dan skenario penempatan lampu yang dinyatakan dalam bentuk geometri.

2. Mengevaluasi Performansi Sistem Evaluasi ditinjau dari nilai SNR dan BER yang sangat fundamental dalam sebuah komunikasi, untuk menyatakan bahwa rancangan telah layak digunakan. Nilai BER perlu dipastikan memenuhi standar yakni $\leq 10^{-3}$.
Tabel 2. Spesifikasi Transmiter, Receiver, dan Konfigurasi Sistem [10].

\begin{tabular}{|c|c|}
\hline Parameter & Nilai \\
\hline Dimensi Ruangan & $6 \times 6 \times 3 \mathrm{~m}^{3}$ \\
\hline $\begin{array}{c}\text { Ketinggian pemasangan lampu } \\
\text { LED }\end{array}$ & $2,85 \mathrm{~m}$ \\
\hline $\begin{array}{c}\text { Transmitted optical power setiap } \\
\text { satu LED }(P t)\end{array}$ & $800 \mathrm{~mW}$ \\
\hline LED array dalam satu lampu & $100(10 \times 10)$ \\
\hline Bandwidth $(B)$ \& Bitrate & $1 \mathrm{Ghz} \& 1 \mathrm{Gbps}$ \\
\hline Modulation Depth $\left(\eta_{\text {ook }}\right)$ & $12,5 \%$ \\
\hline Semiradiation Angle $(\psi)$ & $60^{\circ}$ \\
\hline Ketinggian receiver & $0,85 \mathrm{~m}$ \\
\hline Area photodetector $(A)$ & $1 \mathrm{~cm}$ \\
\hline Responsivitas Photodetector $(R)$ & $0,55 \mathrm{~A} / \mathrm{W}$ \\
\hline Optical filter $\left(T_{s}(\psi)\right)$ & 1,0 \\
\hline FOV $\left(\psi_{C}\right)$ & $70^{\circ}$ \\
\hline Refractive index $(n)$ & 1,5 \\
\hline Dark Current $\left(I_{D C}\right)$ & $5 \mathrm{pA}$ \\
\hline Bandwidth of optical filter $\left(\Delta_{\lambda}\right)$ & $400(380$ to \\
\hline Background spectral irradiance \\
$\left(p_{B S}\right)$ & $580) \mathrm{nm}$ \\
\hline Absolute temperature $(T)$ & $1 / \mathrm{cm}^{2} . \mathrm{nm}$ \\
\hline Open-loop voltage gain $\left(G_{0}\right)$ & $300 \mathrm{~K}$ \\
\hline Channel noise factor $(\Gamma)$ & 10 \\
\hline Transconductance $\left(g_{m}\right)$ & 1,5 \\
\hline $\begin{array}{c}\text { Fixed capacitance of photodetector } \\
\text { per unit area }(\eta)\end{array}$ & $30 \mathrm{mS}$ \\
\hline$\left.{ }^{\circ}\right)$ & $\mathrm{cm}^{2}$ \\
\hline
\end{tabular}

3. Mengukur Estimasi Jarak

Nilai estimasi jarak merepresentasikan jarak antara transmitter dan receiver, hal tersebut dapat dilakukan dengan menggunakan teknik RSS.

4. Menentukan Estimasi Posisi

Nilai estimasi jarak dilakukan dengan memperhatikan beberapa sumber lampu LED. Konsep circular lateration diperlukan untuk menghasilkan nilai estimasi posisi. Estimasi posisi didapatkan menggunakan sifat geometris berdasarkan tiga titik (trilateration) atau lebih (multilateration). Pengambilan trilateration atau multilateration ditinjau dari skenario penggunaan jumlah lampu LED dan bentuk geometri yang digunakan. Setelah itu nilai estimasi posisi dapat diketahui menggunakan metode least linear square.

Tools yang digunakan untuk simulasi adalah software MATLAB R2019b. Beberapa parameter pengukuran untuk analisa, di antaranya ditinjau dari nilai SNR, BER, dan positioning error. Untuk variabel 


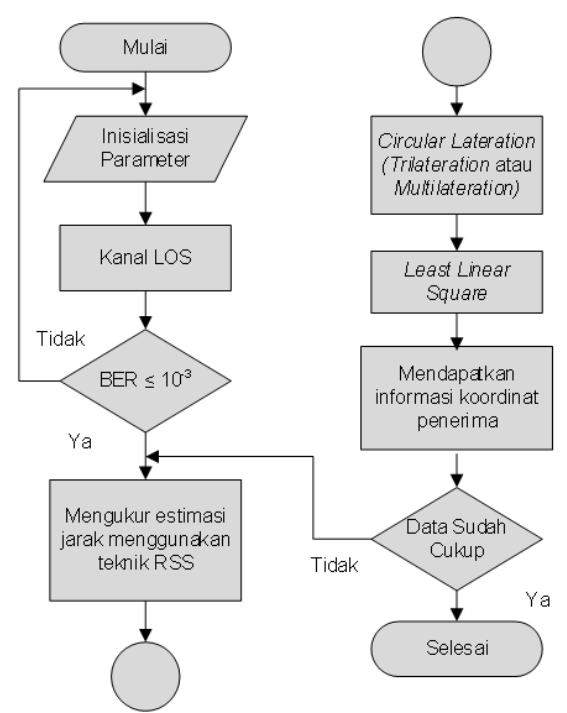

Gambar 3. Diagram Alir Sistem

pengukuran, di antaranya adalah penggunaan jumlah lampu LED, bentuk geometri/penempatan lampu LED, dan lokasi penempatan receiver.

Proses pengambilan data positioning dilakukan pada 37 lokasi berbeda. Dari masing-masing lokasi tersebut dihitung kedekatan antara nilai pengukuran (estimating position) dan nilai sesungguhnya (real position), sehingga dapat disajikan nilai positioning error.

\section{Hasil dan Pembahasan}

\subsection{Signal to Noise Ratio (SNR)}

Performansi sistem ditinjau dari level Signal to Noise Ratio (SNR) yang dapat dinyatakan seperti persamaan (13) berikut [9],

$$
S N R=\frac{R^{2} \cdot P_{L O S}^{2}}{N} .
$$

Gambar 4 menunjukkan hasil SNR yang diperoleh dari simulasi dari masing-masing bentuk geometri. Hasil SNR merupakan kalkulasi pada beberapa sumber transmitter, sehingga terjadi penambahan atau pengurangan level SNR jika dibandingkan dengan individual LED.

Nilai SNR maksimum pada setiap bentuk geometri berbeda, karena hasil distribusi daya terima dari setiap geometri pun tidak sama. Perbedaan tersebut dapat terlihat dari geometri segi enam dan berderet memanjang yang mencapai nilai SNR berkisar $30 \mathrm{~dB}$, dibandingkan dengan geometri bujur sangkar, segitiga, dan segi lima meski dengan parameter yang sama hanya mencapai 25 dB. Pengaruh bentuk geometri terhadap nilai SNR tersebut menunjukkan bahwa pemasangan lampu secara berdekatan atau rapat dapat mengakibatkan penguatan level SNR pada beberapa lokasi tertentu.

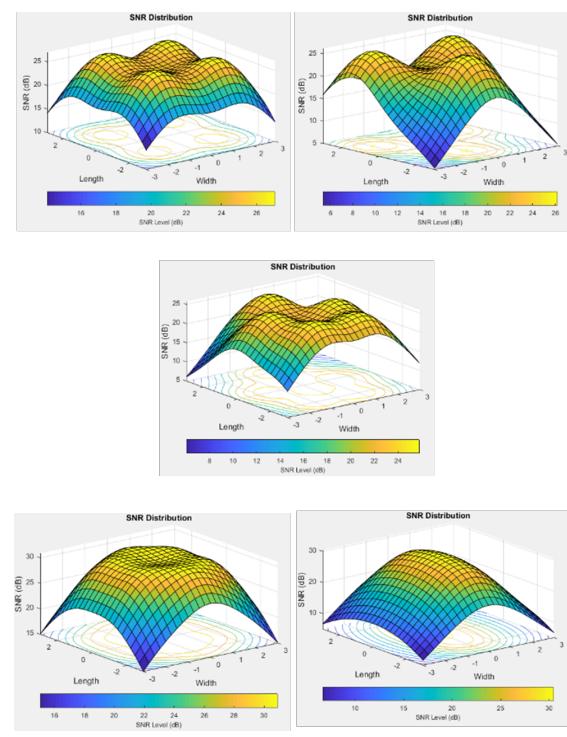

Gambar 4. Hasil SNR dengan bentuk: (a) Bujur Sangkar, dan (b) Segitiga, (c) Segi lima, (d) Segi enam, dan (e) Berderet Memanjang

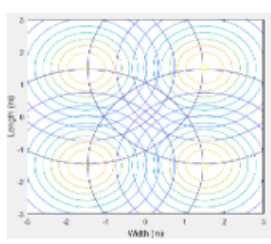

(a)

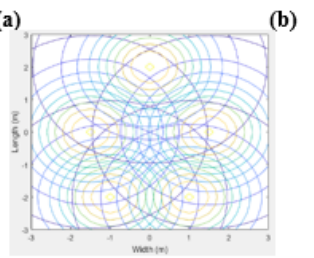

(c)

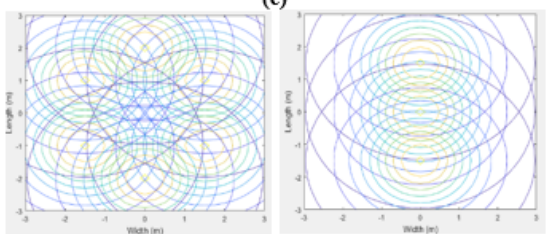

(d)

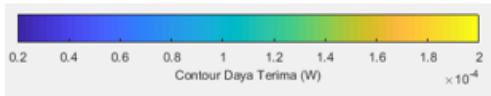

Gambar 5. Contour SNR: (a) Bujur Sangkar, (b) Segitiga, (c) Segi lima, (d) Segi enam, dan (e) Berderet Memanjang 
Gambar 5 menunjukkan contour distribusi daya terima dari masing-masing bentuk geometri.. Perbedaan warna pada beberapa lokasi ruangan menunjukan perbedaan kuat level daya terima yang dihasilkan. Lokasi yang berada dekat sumber cahaya akan mendapatkan level yang lebih tinggi (warna kuning), sedangkan lokasi menjauh dari sumber cahaya akan mendapatkan level yang lebih rendah (warna biru). Representasi daya terima berkaitan erat dengan proses positioning teknik RSS, dimana konsep circular lateration mengambil beberapa referensi sumber lampu LED untuk menghasilkan estimasi posisi. Konsep tersebut biasanya dapat digambarkan dengan posisi receiver yang terlingkupi di antara beberapa transmitter. Ketika hal tersebut dipenuhi, maka proses positioning di lokasi tersebut dapat dilakukan.

\subsection{Positioning}

Positioning error dapat diketahui menggunakan persamaan (14) berikut:

$$
e_{d}=\sqrt{\left(x-x_{e}\right)^{2}+\left(y-y_{e}\right)^{2}}
$$

dengan $e_{d}$ adalah positioningerror, $\left(x_{e}, y_{e}\right)$ adalah estimate position, dan $(x, y)$ adalah real position.

Hasil perbandingan positioning error dari masing-masing bentuk geometri disajikan pada Tabel 3. Pada hasil simulasi yang dilakukan untuk beberapa bentuk geometri, hanya pada geometri berderet memanjang saja proses positioning tidak bisa dilakukan. Hal tersebut dikarenakan faktor lokasi pemasangan lampu LED: dalam kasus ini lokasi pemasangan secara berjajar, sehingga tidak dapat menghasilkan invers matriks dari metode linear least square. Not a Number $(\mathrm{NaN})$ disini memiliki arti bahwa hasil akar kuadrat memiliki bilangan imajiner, sehingga tidak dapat direpresentasikan sebagai bilangan riil. Untuk mengatasi masalah ini, lokasi lampu dipasang secara tidak sejajar. Tetapi, jika tetap akan menggunakan berderet memanjang, proses positioning akan menjadi tidak presisi. Terkait metode yang sesuai pada penelitian ini, tidak disarankan untuk menggunakan bentuk geometri berderet memanjang untuk implementasi IPS.

Lokasi $(0,0)$ merupakan kedudukan receiver dengan jarak yang relatif sama antara masing-masing lampu pada semua bentuk geometri, dan hal tersebut menghasilkan error positioning yang lebih kecil di antara lokasi lainnya. Error minimum yang didapatkan pada bentuk geometri bujur sangkar dengan nilai $0 \mathrm{~m}$. Maksimum error didapatkan pada bentuk geometri segitiga dengan nilai $9,48 \times 10^{-05} \mathrm{~m}$. Selain itu, rata-rata error terkecil dihasilkan dari bentuk geometri segi enam, yakni sebesar $1,53 \times 10^{-05} \mathrm{~m}$.
Tabel 3. Perbandingan Error Psotioning RSS

\begin{tabular}{|c|c|c|c|c|}
\hline $\begin{array}{c}\text { Bentuk } \\
\text { Geometri }\end{array}$ & Teknik & $\begin{array}{c}\text { Min } \\
\text { Error } \\
(\mathbf{m})\end{array}$ & $\begin{array}{c}\text { Maks } \\
\text { Error } \\
\text { (m) }\end{array}$ & $\begin{array}{c}\text { Mean } \\
\text { Error } \\
(\mathrm{m})\end{array}$ \\
\hline Segitiga & \multirow{2}{*}{$\begin{array}{c}\text { Trilater } \\
\text { al }\end{array}$} & $\begin{array}{c}7,85 \mathrm{x} \\
10^{-07}\end{array}$ & $\begin{array}{c}9,48 \mathrm{x} \\
10^{-05}\end{array}$ & $\begin{array}{c}1,95 \mathrm{x} \\
10^{-05}\end{array}$ \\
\hline $\begin{array}{c}\text { Berderet } \\
\text { Memanjang }\end{array}$ & & NaN & $N a N$ & $\mathrm{NaN}$ \\
\hline $\begin{array}{c}\text { Bujur } \\
\text { Sangkar }\end{array}$ & \multirow{3}{*}{$\begin{array}{c}\text { Multilat } \\
\text { eral }\end{array}$} & 0 & $\begin{array}{c}6,97 \mathrm{x} \\
10^{-05} \\
\end{array}$ & $\begin{array}{c}1,79 \mathrm{x} \\
10^{-05} \\
\end{array}$ \\
\hline Segi li & & $\begin{array}{c}4,70 \mathrm{x} \\
10^{-08}\end{array}$ & $\begin{array}{c}6,02 \times \\
10^{-05}\end{array}$ & $\begin{array}{c}1,58 \mathrm{x} \\
10^{-05}\end{array}$ \\
\hline Segi enam & & $\begin{array}{c}4,60 \mathrm{x} \\
10^{-08} \\
\end{array}$ & $\begin{array}{c}5,83 \mathrm{x} \\
10^{-05} \\
\end{array}$ & $\begin{array}{c}1,53 \mathrm{x} \\
10^{-05}\end{array}$ \\
\hline
\end{tabular}

\section{Kesimpulan}

Penggunaan teknik trilateral dan multilateral dengan perbedaan bentuk geometri berpengaruh terhadap hasil positioning. Pengujian positioning teknik RSS pada 37 lokasi berbeda menunjukkan bahwa geometri segi enam memiliki rata-rata positioning error lebih kecil dibandingkan geometri yang lain, yakni sebesar $1,53 \times 10^{-05} \mathrm{~m}$. Semakin banyak lampu LED atau poin referensi dengan rentang jarak lampu yang lebih rapat dapat menghasilkan positioning yang lebih baik. Di sisi lain, penggunaan bentuk geometri berderet memanjang tidak disarankan untuk diaplikasikan pada IPS sesuai konsep sistem pada penelitian ini. Hal tersebut karena posisi penempatan LED yang sejajar menyebabkan bilangan menjadi imajiner pada proses metode least linear square sehingga proses positioning tidak terbaca.

\section{Daftar Pustaka}

[1] The indoor influence regional report europe. [Online]. Available: https: //www.ericsson.com/res/docs/2015/consumerlab/ ericsson-consumerlab-the-indoor-influenceeurope. pdf.

[2] M. Nakajima and S. Haruyama, "New indoor navigation system for visually impaired people using visible light communication," EURASIP Journal on Wireless Communications and Networking, vol. 2013, no. 1, pp. 1-10, 2013.

[3] D. R. Rizkiyani, D. Darlis, and R. A. Piramadhi, "Rancang bangun purwarupa tongkat pemandu untuk tunanetra berbasis hybrid visible light communication dengan keluaran suara," eProceedings of Applied Science, vol. 5, no. 1, 2019.

[4] M. A. Afzal, D. He, Z. Zhu, and Y. Yang, "Performance evaluation of wi-fi bluetooth low energy \& li-fi technology in indoor positioning," in 2018 IEEE 23rd International Conference on 
Digital Signal Processing (DSP). IEEE, 2018, pp. $1-5$.

[5] S. Afifah, S. Angelina, P. Susamti, R. Priramadhi, and D. Darlis, "Energy efficient transmitter for guided indoor navigation using visible light," in IOP Conference Series: Materials Science and Engineering, vol. 434, no. 1. IOP Publishing, 2018, p. 012213.

[6] H. Haas, L. Yin, Y. Wang, and C. Chen, "What is lifi?" Journal of lightwave technology, vol. 34, no. 6, pp. 1533-1544, 2015.

[7] F. Zafari, A. Gkelias, and K. K. Leung, "A survey of indoor localization systems and technologies," IEEE Communications Surveys \& Tutorials, vol. 21, no. 3, pp. 2568-2599, 2019.

[8] W. Zhang, M. S. Chowdhury, and M. Kavehrad, "Asynchronous indoor positioning system based on visible light communications," Optical Engineering, vol. 53, no. 4, p. 045105, 2014.
[9] G. Archenhold, "Health and safety of artificial lighting," Mondo Arc, vol. 63, pp. 111-118, 2011.

[10] M. Abd Elkarim, N. A. Mohammed, and M. H. Aly, "Exploring the performance of indoor localization systems based on vlc-rssi, including the effect of nlos components using two light-emitting diode lighting systems," Optical Engineering, vol. 54, no. 10, p. 105110, 2015.

[11] A. Shlomi, Visible Light Communication.

[12] Z. Wang, Q. Wang, W. Huang, and Z. Xu, Visible light communications: Modulation and signal processing. John Wiley \& Sons, 2017.

[13] X. Zhang, J. Duan, Y. Fu, and A. Shi, "Theoretical accuracy analysis of indoor visible light communication positioning system based on received signal strength indicator," Journal of Lightwave Technology, vol. 32, no. 21, pp. 35783584, 2014. 